Pacific Journal of Mathematics

LOCALE GEOMETRY 


\title{
LOCALE GEOMETRY
}

\author{
B. J. DAY
}

We commence with a locale $\mathscr{L}$ (that is, a complete Heyting algebra) and introduce the notion of an $\mathscr{L}$-valued betweenness relation on a set. The concept of an $\mathscr{L}$-valued geometry is then formulated and the relevant versions of the Radon, Helly and Carathéodory theorems are proved.

Introduction. The abstract theory of join systems was developed by W. Prenowitz [8] and [9] as an aid to studying descriptive and spherical geometries. This notion of join system has since been further developed by V. W. Bryant and R. J. Webster [1] to enable the corresponding axiomatic treatment of such results as the Radon, Helly and Carathéodory theorems. It is this aspect of the theory with which the present article is concerned.

We commence this article by extending the notion of a join system so that it is no longer necessarily two-valued. More precisely, given a locale lattice $\mathscr{L}$, we introduce the notion of an $\mathscr{L}$-valued betweenness relation (-,-,-): $X \times X \times X \rightarrow \mathscr{L}$ on a set $X$; if $(x, y, z)=p \in \mathscr{L}$ we might say that the point $z$ lies on the segment $(x, y)$ with "probability $p$ ". This loose description is related to theories of multivalued logic which arise in topos theory. Indeed, one can develop join systems in a reasonably complete topos in terms of multivalued join systems over the category of sets; see $\S 4$. These notions, in turn, give rise to the forms of the Radon, Helly and Carathéodory theorems dicussed in $\S 3$.

We emphasize here that, in this preliminary article, we do not deal with multigroups (after W. Prenowitz) nor do we enter into all aspects of dimension theory (after V. W. Bryant and R. J. Webster). Also we leave the proof of the more basic elementary deductions as simple exercises for the reader; these results are used without reference.

1. $\mathscr{L}$-forms. Let $\mathscr{L}$ be a locale and let $X$ be a set. A symmetric $\mathscr{L}$-form on $X$ is a function $X(-,-): X \times X \rightarrow \mathscr{L}$ such that $X(x, x)=1, X(x, y)=X(y, x), \sup _{y} X(x, y) \wedge X(y, z)=X(x, z)$. A functional on $X$ is a set map $A: X \rightarrow \mathscr{L}$ such that $A=\sup _{x} A(x) \wedge$ $X(x,-)$. A singleton, or point is a functional of the form $\bar{x}=X(x,-)$ : $X \rightarrow \mathscr{L}$. Thus each functional is an "expansion of singletons" or an "internal colimit of points". For notational convenience we shall represent $\bar{x}$ simply by $x$ unless we wish to emphasize the distinction.

The ordered set of functionals on $X$ is denoted $\mathrm{Fnl}(X, \mathscr{L})$; it 
is a sublocale of $\mathscr{P}^{x}$. Note that if $A: X \rightarrow \mathscr{L}$ is any functional then $A \geqq x$ iff $A(x)=1$.

A map of $\mathscr{L}$-forms $f:(X, X(-,-)) \rightarrow\left(X^{\prime}, X^{\prime}(-,-)\right)$ is a set map $f: X \rightarrow X^{\prime}$ such that $X^{\prime}(f x, f y)=X(x, y)$ for all $x, y \in X$.

2. Convexity spaces. An $\mathscr{L}$-preconvexity space is a set $X$ equipped with a symmetric $\mathscr{L}$-form $X(-,-): X \times X \rightarrow \mathscr{L}$ and a map $(-,-,-): X \times X \times X \rightarrow \mathscr{L}$ which is functional in each variable separately. A map of preconvexity space is a map $f: X \rightarrow X^{\prime}$ of $\mathscr{L}$-forms such that $(f x, f y, f z)=(x, y, z)$ for all $x, y, z \in X$. The resultant category is denoted $\mathscr{L} p c$.

Given $X \in \mathscr{L} p c$ we define the convolutions:

$$
\begin{aligned}
& A B(x)=\sup _{y, z} A(y) \wedge B(z) \wedge(y, z, x) \\
& A / B(x)=\sup _{y, z} A(y) \wedge B(z) \wedge(z, x, y) .
\end{aligned}
$$

Then $\bar{x} \bar{y}=(x, y,-)$ is the join of $x$ to $y$, while $\bar{x} / \bar{y}=(y,-, x)$ is the extension of $x$ by $y$.

An interesting consequence of these definitions is the following Kan-extension principle: If $f$ and $g$ are polynomials of $n$-variables in the convolution operations $A B$ and $A / B$, and $f\left(x_{1}, \cdots, x_{n}\right) \geqq$ $g\left(x_{1}, \cdots, x_{n}\right)$ for all points $x_{1}, \cdots, x_{n}$ then $f\left(A_{1}, \cdots, A_{n}\right) \geqq g\left(A_{1}, \cdots, A_{n}\right)$ for all functionals $A_{1}, \cdots, A_{n}$.

An $\mathscr{L}$-convexity space is an $\mathscr{L}$-preconvexity space which satisfies the following axioms:

C1. (symmetry) $(x, y, z)=(y, x, z)$.

C2. (idempotence) $(a, a, x)=X(a, x), \quad(a, x, a)=X(a, x)$.

C3. (associativity) $\sup _{w}(y, v, w) \wedge(w, z, x)=\sup _{w}(v, z, w) \wedge(y, w, x)$.

C4. (transposition) $\sup _{w}(z, w, y) \wedge(x, w, v) \leqq \sup _{w}(x, y, w) \wedge(z, v, w)$.

C5. (cancellation) $\sup _{w}(x, y, w) \wedge(x, z, w)=X(y, z) \vee(x, y, z) \vee(x, z, y)$.

The full subcategory of $\mathscr{L} p c$ comprising the $\mathscr{L}$-convexity spaces is denoted $\mathscr{L} c$.

The following propositions are immediate from the axioms.

Proposition. $\quad x y / x z=y / z \vee x y / z \vee y / x z$.

Proposition. $A B=B A,(A B) C=A(B C), A \leqq A A$ and $A \leqq A / A$, $(A / B) / C=A / B C, A(B / C) \leqq A B / C$, and $A /(B / C) \leqq A C / B$. 
Proposition. (i ) $x A / x=A \vee x A \vee A / x$,

(ii) $x A / x B=A / B \vee x A / B \vee A / x B$,

(iii) $x / x B=x / B$.

The following relations are easily deduced by iterated use of the preceding proposition:

LEMMA 2.1 (Radon).

$$
\frac{x_{0} \cdots x_{n}}{x_{0} \cdots x_{n}}=\vee\left\{x_{i_{0}} \cdots x_{i_{r}}, \frac{x_{i_{0}} \cdots x_{i_{s}}}{x_{i_{s+1}} \cdots x_{i_{r}}} ; i_{0}, \cdots, i_{r} \text { all different }\right\} \text {. }
$$

Lemma 2.2 (Carathéodory). For $n \geqq r$

$$
\begin{gathered}
\frac{x_{0} \cdots x_{n}}{x_{0} \cdots x_{r}}=\vee\left\{x_{i_{0}} \cdots x_{i_{p}}, \frac{x_{i_{0}} \cdots x_{i_{q}}}{x_{i_{q+1}} \cdots x_{i_{p}}} ; i_{0}, \cdots, i_{p}\right. \text { all different and } \\
p-q \leqq r\} .
\end{gathered}
$$

For the remainder of this section we shall suppose that $X$ is a fixed $\mathscr{L}$-convexity space. A functional $A: X \rightarrow \mathscr{L}$ is said to be convex if $A A=A$; note that singletons are convex (C2). The convex hull of a functional $A$ is defined to be $\bigvee_{n=1}^{\infty} A^{n}$.

Proposition. (i ) If $A_{1}, \cdots, A_{n}$ are convex then so are $A_{1} \cdots A_{n}$ and $A_{1} / A_{2}$.

(ii) The convex hull of a functional $A$ is the intersection in Fnl $(X, \mathscr{L})$ of all the convex functionals which contain $A$.

A functional $A: X \rightarrow \mathscr{L}$ is said to be linear if it is convex and $A / A=A$. The linear hull of a functional $A$ is defined to be $\mathrm{V}_{m, n=1}^{\infty} A^{m} / A^{n}$ and is denoted by $[A]$.

Proposition. (i) The linear hull of a functional $A$ is the intersection in $\mathrm{Fnl}(X, \mathscr{L})$ of all the linear functionals which contain $A$.

(ii) If $A$ is convex then $A / A$ is linear.

(iii) If $A$ is convex then $[A]=A / A$.

(iv) $\left[x_{0} \cdots x_{n}\right]=x_{0} \cdots x_{n} / x_{0} \cdots x_{n}$.

3. The Radon, Helly and Carathéodory theorems. Henceforth in this section we suppose that $X$ is a fixed $\mathscr{L}$-convexity space. We shall also suppose that whenever we consider a set $\left\{x_{0}, \cdots, x_{n}\right\}$ then the $\bar{x}_{i}$ 's are distinct (recall that $\bar{x}_{i}$ is denoted simply by $x_{i}$ ). The product functional of $M=\left\{x_{1}, \cdots, x_{n}\right\}$ is denoted by $M^{*}=$ $x_{1} \cdots x_{n}$. 
A set $\left\{x_{0}, \cdots, x_{n}\right\}$ of singletons is said to be strongly dependent if there exists an $i(0 \leqq i \leqq n)$ such that $\left[x_{0} \cdots x_{i-1} x_{i+1} \cdots x_{n}\right]\left(x_{i}\right)=1$. If every set of $n+2$ singletons is strongly dependent then we say that $X$ has dimension $\leqq n$.

THEOREM 3.1 (Radon). If $\left\{x_{0}, \cdots, x_{n+1}\right\}$ is a set of $n+2$ singletons in a convexity space of dimension $\leqq n$ then there exist disjoint nonempty subsets $M$ and $N$ of $\left\{x_{0}, \cdots, x_{n+1}\right\}$ such that $M^{*} \wedge N^{*} \neq 0$.

Proof. The $n+2$ points lie in a space of dimension $\leqq n$ so we may assume, without loss of generality, that $\left[x_{1} \cdots x_{n+1}\right]\left(x_{0}\right)=1$. By Lemma 2.1 we have either $N^{*}\left(x_{0}\right) \neq 0$ where $N$ is a subset of $\left\{x_{1}, \cdots, x_{n+1}\right\}$ or $N^{*} / P^{*}\left(x_{0}\right) \neq 0$ where $N$ and $P$ are nonempty disjoint subsets of $\left\{x_{1}, \cdots, x_{n+1}\right\}$. Thus the result follows from taking $M=x_{0}$ in the first case and $M=\left\{x_{0}, P\right\}$ in the second case. In the first case we have $N^{*}\left(x_{0}\right) \neq 0$ implies $x_{0} \wedge N^{*} \neq 0$ since $x_{0} \wedge N^{*}=0$ implies $x_{0}\left(x_{0}\right) \wedge N^{*}\left(x_{0}\right)=0$ implies $N^{*}\left(x_{0}\right)=0$, and in the second case we have $N^{*} / P^{*}\left(x_{0}\right) \neq 0$ implies $\sup _{u, v} N^{*}(u) \wedge P^{*}(v) \wedge\left(v, x_{0}, u\right) \neq 0$ implies $\sup _{u} N^{*}(u) \wedge x_{0} P^{*}(u) \neq 0$ implies there exists a $u \in X$ such that $N^{*}(u) \wedge x_{0} P^{*}(u) \neq 0$.

THEOREM 3.2 (Helly). If $A_{0}, \cdots, A_{n+1}$ is a family of $n+2$ convex functionals on a convexity space of dimension $\leqq n$ and any $n+1$ of these functionals intersect with certainty then all the functionals have a nonzero intersection.

Proof. For each $i(0 \leqq i \leqq n+1)$ there exists, by hypothesis, a singleton $x_{i}$ such that

$$
x_{i} \leqq A_{0} \wedge \cdots \wedge A_{i-1} \wedge A_{i+1} \wedge \cdots \wedge A_{n+1} .
$$

If $x_{i}=x_{j}$ for some $i \neq j$ then $x_{i} \leqq A_{0} \wedge \cdots \wedge A_{n+1}$ and the result follows. Otherwise the singletons $x_{i}$ are distinct so that, by Theorem 3.1, there exist nonempty disjoint subsets $M$ and $N$ of $\left\{x_{0}, \cdots, x_{n+1}\right\}$ such that $M^{*} \wedge N^{*} \neq 0$. Because $M^{*} \wedge N^{*} \leqq A_{0} \wedge \cdots \wedge A_{n+1}$ the result follows.

LEMMA 3.3. If $x \leqq x_{0} \cdots x_{n}$ and $M^{*} / N^{*}(x) \neq 0$ where $M$ and $N$ are nonempty disjoint subsets of $\left\{x_{0}, \cdots, x_{n}\right\}$ then there exists a proper subset $P$ of $\left\{x_{0}, \cdots, x_{n}\right\}$ such that $P^{*}(x) \neq 0$.

Proof. The proof is by induction on the cardinal of $N$. Firstly, if $|N|=1$, assume $N=x_{0}$ without loss of generality. Let $S=$ $\left\{x_{1}, \cdots, x_{n}\right\}$. Now $x \leqq x_{0} \cdots x_{n}$ implies $x_{0} \leqq x / S^{*}$. Moreover, if 
$M^{*} / x_{0}(x) \neq 0$ where $M$ is a nonempty subset of $S$ then $S^{*} / x_{0}(x) \neq 0$. Thus $0 \neq S^{*} / x_{0}(x) \leqq S^{*} /\left(x / S^{*}\right) \leqq S^{*} / x(x)$ since $S^{*}$ is convex. But $S^{*} / x(x) \neq 0$ implies $\sup _{u} S^{*}(u) \wedge(x, x, u) \neq 0$ implies $S^{*}(x) \neq 0$ so $x_{1} \cdots x_{n}(x) \neq 0$. Now suppose $|N|=r+1$ and $x \leqq x_{0} \cdots x_{n}$ and $M^{*} / N^{*}(x) \neq 0$. Without loss of generality let $N=\left\{x_{0}, \cdots, x_{r}\right\}$. The conditions $x \leqq x_{0} \cdots x_{n}$ and $M^{*} / x_{0} \cdots x_{r}(x) \neq 0$ imply that $x_{1} \cdots x_{n}$ $\mid x_{1} \cdots x_{r}(x) \neq 0$ since $x \leqq x_{0} \cdots x_{n}$ implies $x_{0} \leqq x / x_{1} \cdots x_{n}$. Thus $0 \neq$ $M^{*} / x_{0} \cdots x_{r}(x) \leqq\left(x_{1} \cdots x_{n}\right) /\left(x / x_{1} \cdots x_{n}\right) x_{1} \cdots x_{r}(x)$ implies $x_{1} \cdots x_{n}$ $\mid x x_{1} \cdots x_{r}(x) \neq 0$. But $x_{1} \cdots x_{n} / x x_{1} \cdots x_{r}(x)=\left(\left(x_{1} \cdots x_{n} / x_{1} \cdots x_{r}\right) / x\right)(x)$ so $x_{1} \cdots x_{n} / x_{1} \cdots x_{r}(x) \neq 0$. Thus, by Lemma 2.2 , either $P^{*}(x) \neq 0$ where $P$ is a nonempty subset of $\left\{x_{1}, \cdots, x_{n}\right\}$ or $Q^{*} / R^{*}(x) \neq 0$ where $Q$ and $R$ are nonempty disjoint subsets of $\left\{x_{1}, \cdots, x_{n}\right\}$ and $|R| \leqq r$.

THeOREM 3.4 (Carathéodory). If $x \leqq x_{0} \cdots x_{n+1}$ for singletons in a convexity space of dimension $\leqq n$ then there exists a proper subset $P$ of $\left\{x_{0}, \cdots, x_{n+1}\right\}$ such that $P^{*}(x) \neq 0$.

Proof. Without loss of generality let us assume $x_{0} \leqq\left[x_{1} \cdots x_{n+1}\right]$. Thus, by Lemma 2.2, either $M^{*}\left(x_{0}\right) \neq 0$ where $M$ is a subset of $\left\{x_{1}, \cdots, x_{n+1}\right\}$ or $M^{*} / N^{*}\left(x_{0}\right) \neq 0$ where $M$ and $N$ are nonempty disjoint subsets of $\left\{x_{1}, \cdots, x_{n+1}\right\}$. In the first case $x_{1} \cdots x_{n+1}(x) \neq 0$ and in the second case $x_{1} \cdots x_{n+1} / N^{*}(x) \neq 0$. In order to establish these assertions let $S=\left\{x_{1}, \cdots, x_{n+1}\right\}$. In the first case note that $M^{*}\left(x_{0}\right) \neq 0$ implies $S^{*}\left(x_{0}\right) \neq 0$. But $x \leqq x_{0} S^{*}$ implies $x_{0} \leqq x / S^{*}$ thus

$$
\begin{aligned}
0 \neq & S^{*}\left(x_{0}\right)=\sup _{u} S^{*}(u) \wedge X\left(x_{0}, u\right)=\sup _{u} S^{*}(u) \wedge x_{0}(u) \\
& \leqq \sup _{u} S^{*}(u) \wedge x / S^{*}(u)=\sup _{v w} S^{*}(u) \wedge x(v) \wedge S^{*}(w) \wedge(w, u, v) \\
& =\sup _{u} S^{*}(u) \wedge S^{*}(w) \wedge(w, u, x)=S^{*}(x)
\end{aligned}
$$

since $S^{*}$ is convex. Thus $x_{1} \cdots x_{n+1}(x) \neq 0$. In the second case we have to show that $\sup _{u, v} S^{*}(u) \wedge N^{*}(v) \wedge(v, x, u)=\sup _{u} S^{*}(u) \wedge$ $x N^{*}(u) \neq 0$. But we have

$$
\begin{aligned}
0 \neq & \sup _{u} S^{*}(u) \wedge x_{0} N^{*}(u) \leqq \sup _{u} S^{*}(u) \wedge\left(x / S^{*}\right) N^{*}(u) \\
& \leqq \sup _{u} S^{*}(u) \wedge x N^{*} / S^{*}(u)=\sup _{v w} S^{*}(u) \wedge x N^{*}(v) \wedge S^{*}(w) \wedge(w, u, v) \\
& =\sup _{v} S^{*}(v) \wedge x N^{*}(v)
\end{aligned}
$$

since $S^{*}$ is convex, as required. Thus either $P^{*}(x) \neq 0$ where $P$ is a nonempty subset of $\left\{x_{1}, \cdots, x_{n+1}\right\}$ or $M^{*} / N^{*}(x) \neq 0$ where $M$ and $N$ are nonempty disjoint subsets of $\left\{x_{1}, \cdots, x_{n+1}\right\}$. The first case is as required while in the second case the result follows from Lemma 3.3 . 
REMARK. In the case $\mathscr{L}=2$ these results reduce to the generalizations of Radon, Helly and Carathéodory theorems discussed by Bryant and Webster [1].

4. Examples. Examples of $\mathscr{L}$-convexity spaces can be generated by various different processes. Perhaps the most basic of these arises from the fact that $\mathscr{L} c$ is closed under colimits in $\mathscr{L} p c$ and $\mathscr{L} c$ has a generator (namely the one-point space). Thus, by the special adjoint-functor theorem (Mac Lane [7]), the inclusion $\mathscr{L} c \subset \mathscr{L} p c$ has a right adjoint, so every $\mathscr{L}$-preconvexity space has a canonical associated convexity space.

If $X$ is an $\mathscr{L}$-convexity space then $X^{Z}$ is an $\mathscr{L}^{z}$-convexity space for all sets $Z$. Thus it is consistent to define, in a topos $\mathscr{E}$ (see Johnstone [6]) for which each $\mathscr{E}(Z, \Omega)$ is complete as a Heyting algebra, an $\Omega$-convexity space as a map (-, -, -): $X \times X \times X \rightarrow \Omega$ in $\mathscr{E}$ such that $\mathscr{E}(Z, X)$ is an $\mathscr{E}(Z, \Omega)$-convexity space for all $Z \in \mathscr{E}$.

Another example arises as follows. Call a functional $A: X \rightarrow \mathscr{L}$ left exact if $A(x) \wedge A(y)=\sup _{a} A(a) \wedge X(a, x) \wedge X(a, y)$ and $\sup _{a} A(a)=1$; a left-exact functional is always linear. Given $X \in \mathscr{L} c$ define $\hat{X}$ to be the set of all left-exact functionals from $X$ to $\mathscr{L}$. On $\hat{X}$ define $\hat{X}(A, B)=\sup _{x} A(x) \wedge B(x)$ and $(A, B, C)=\sup _{x, y, z} A(x) \wedge$ $B(y) \wedge C(z) \wedge(x, y, z)$. Then $\hat{X}$ is an $\mathscr{L}$-convexity space and $X \rightarrow \hat{X}$ is a map of $\mathscr{L}$-convexity spaces.

Finally, if $X \times X \times X \rightarrow \mathscr{L}_{\lambda}, \lambda \in \Lambda$, represents a set of convexity space structures on a set $X$, one for each $\lambda \in \Lambda$, the induced map $X \times X \times X \rightarrow \Pi_{1} \mathscr{L}_{\lambda}$ is a convexity-space structure. This fact allows the construction of $\mathscr{L}$-valued convexity spaces from families of classical convexity spaces on $X$ (see, for example, quasiconvexities $[5])$.

\section{REFERENCES}

1. V.W. Bryant and R.J. Webster, Generalisations of the theorems of Radon, Helly and Carathéodory, Monatsch. Math., 73 (1969), 309-315.

2. - Convexity spaces I: The basic properties, J. Math. Anal. Appl., 37 (1972), 206-213.

3. - Convexity spaces II: Separation, J. Math. Anal. Appl., 43 (1973), 321-327.

4. - Convexity spaces III: Dimension, J. Math. Anal. Appl., 57 (1977), 382-392.

5. J. W. Green and W. Gustin, Quasiconvex sets, Canad. J. Math., 2 (1950), 489-507.

6. P. T. Johnstone, Topos Theory, London Math. Soc. Monographs No. 10, Academic Press, London, New York, San Francisco, 1977.

7. S. Mac Lane, Categories for the working mathematician, Graduate Texts in Mathematics, 5 Springer-Verlag, Berlin, Heidelberg, New York, 1971.

8. Walter Prenowitz, Descriptive geometries as multigroups, Trans. Amer. Math. Soc., 59 (1946), 333-380. 
9. Walter Prenowitz, A contemporary approach to classical geometry, H. E. Slaught Memorial Paper No. 9, Amer. Math. Monthly, 68 (1961), 1-67.

Received November 21, 1978.

UNIVERSITY OF SYDNEY

N.S.W. 2006, Australia 



\title{
PACIFIC JOURNAL OF MATHEMATICS
}

\section{EDITORS}

DONALD BABBITT (Managing Editor)

University of California

Los Angeles, CA 90024

\section{HUGO RossI}

University of Utah

Salt Lake City, UT 84112

C. C. MOORE and ANDREW OGG

University of California

Berkeley, CA 94720

\section{J. DUGUNDJI}

Department of Mathematics University of Southern California Los Angeles, CA 90007

R. FINN and J. Milgram

Stanford University Stanford, CA 94305

\section{ASSOCIATE EDITORS}
E. F. BECKENBACH
B. H. NeUmanN
F. WOLF
K. YosHIDA

\section{SUPPORTING INSTITUTIONS}

\author{
UNIVERSITY OF BRITISH COLUMBIA \\ CALIFORNIA INSTITUTE OF TECHNOLOGY \\ UNIVERSITY OF CALIFORNIA \\ MONTANA STATE UNIVERSITY \\ UNIVERSITY OF NEVADA, RENO \\ NEW MEXICO STATE UNIVERSITY \\ OREGON STATE UNIVERSITY \\ UNIVERSITY OF OREGON
}

\author{
UNIVERSITY OF SOUTHERN CALIFORNIA \\ STANFORD UNIVERSITY \\ UNIVERSITY OF HAWAII \\ UNIVERSITY OF TOKYO \\ UNIVERSITY OF UTAH \\ WASHINGTON STATE UNIVERSITY \\ UNIVERSITY OF WASHINGTON
}

The Supporting Institutions listed above contribute to the cost of publication of this Journal, but they are not owners or publishers and have no responsibility for its content or policies.

Mathematical papers intended for publication in the Pacific Journal of Mathematics should be in typed form or offset-reproduced, (not dittoed), double spaced with large margins. Please do not use built up fractions in the text of the manuscript. However, you may use them in the displayed equations. Underline Greek letters in red, German in green, and script in blue. The first paragraph or two must be capable of being used separately as a synopsis of the entire paper. Please propose a heading for the odd numbered pages of less than 35 characters. Manuscripts, in triplicate, may be sent to any one of the editors. Please classify according to the scheme of Math. Reviews, Index to Vol. 39. Supply name and address of author to whom proofs should be sent. All other communications should be addressed to the managing editor, or Elaine Barth, University of California, Los Angeles, California, 90024.

50 reprints to each author are provided free for each article, only if page charges have been substantially paid. Additional copies may be obtained at cost in multiples of 50 .

The Pacific Journal of Mathematics is issued monthly as of January 1966. Regular subscription rate: $\$ 84.00$ a year (6 Vols., 12 issues). Special rate: $\$ 42.00$ a year to individual members of supporting institutions.

Subscriptions, orders for numbers issued in the last three calendar years, and changes of address should be sent to Pacific Journal of Mathematics, P.O. Box 969, Carmel Valley, CA 93924, U.S.A. Older back numbers obtainable from Kraus Periodicals Co., Route 100, Millwood, NY 10546.

PUBLISHED BY PACIFIC JOURNAL OF MATHEMATICS, A NON-PROFIT CORPORATION

Printed at Kokusai Bunken Insatsusha (International Academic Printing Co., Ltd.). 8-8, 3-chome, Takadanobaba, Shinjuku-ku, Tokyo 160, Japan.

Copyright (C) 1979 by Pacific Journal of Mathematics Manufactured and first issued in Japan 


\section{Pacific Journal of Mathematics}

\section{Vol. 83, No. $2 \quad$ April, 1979}

Patrick Robert Ahern, On a theorem of Hayman concerning the derivative of a

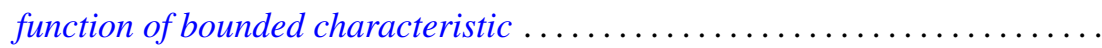

Walter Allegretto, Finiteness of lower spectra of a class of higher order elliptic

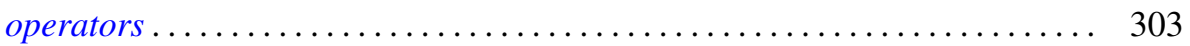

Leonard Asimow, Superharmonic interpolation in subspaces of $C_{c}(X) \ldots \ldots 11$

Steven F. Bellenot, An anti-open mapping theorem for Fréchet spaces . . . . . . . 325

B. J. Day, Locale geometry. . . . . . . . . . . . . . . . . . . . . . . . . . 333

John Erik Fornaess and Steven Krantz, Continuously varying peaking

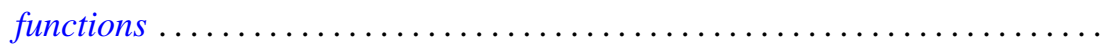

Joseph Leonide Gerver, Long walks in the plane with few collinear points ......

Joseph Leonide Gerver and Lawrence Thom Ramsey, On certain sequences of

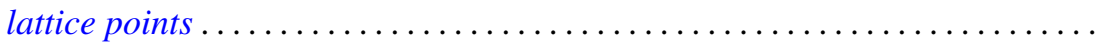

John R. Graef, Yuichi Kitamura, Takaŝi Kusano, Hiroshi Onose and Paul Winton

Spikes, On the nonoscillation of perturbed functional-differential

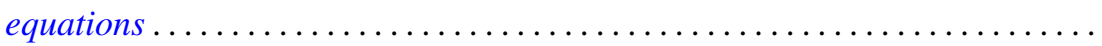

James A. Huckaba and James M. Keller, Annihilation of ideals in commutative

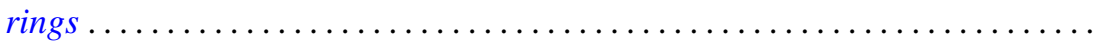

Anzelm Iwanik, Norm attaining operators on Lebesgue spaces . . . . . . . . . . .

Surjit Singh Khurana, Pointwise compactness and measurability . . . .......... 387

Charles Philip Lanski, Commutation with skew elements in rings with

involution.

Hugh Bardeen Maynard, A Radon-Nikodým theorem for finitely additive bounded

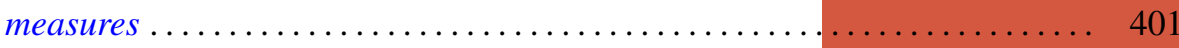

Kevin Mor McCrimmon, Peirce ideals in Jordan triple systems ..

Sam Bernard Nadler, Jr., Joseph E. Quinn and N. Stavrakas, Hyperspaces of compact convex sets.

Ken Nakamula, An explicit formula for the fundamental units of a real pure

sextic number field and its Galois closure ............

Vassili Nestoridis, Inner functions invariant connected components . .

Vladimir I. Oliker, On compact submanifolds with nondegenerate parallel

normal vector fields.

Lex Gerard Oversteegen, Fans and embeddings in the plane.

Shlomo Reisner, On Banach spaces having the property G.L

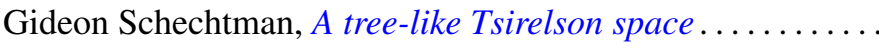

Helga Schirmer, Fix-finite homotopies . . . . . . . . . . . .

Jeffrey D. Vaaler, A geometric inequality with applications to linear forms . .

William Jennings Wickless, $T$ as an $\mathscr{G}$ submodule of $G$.....

Kenneth S. Williams, The class number of $Q(\sqrt{-p})$ modulo 4 , for $p \equiv 3$ (

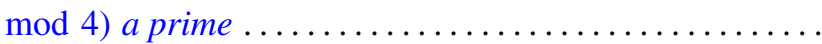

